\title{
Onomatopéias e interjeições em histórias em quadrinhos em língua alemã
}

\section{Selma Meireles*}

\begin{abstract}
Interjections and onomatopoeia receive very little attention from language studies, and grammars and dictionaries very often restrict themselves to presenting a stereotypical definition and a few examples. Loathed in traditional literature, such expressions found their "natural habitat" in comics, where they became indispensable to the language of this genre. This short experiment about interjections and onomatopoeia in mangas (Japanese comics) translated into German and Brazilian Portuguese shows that, although there are basic phonetic patterns common to both languages according to what they refer to, the found interjections and onomatopoeia differ a lot, which stresses their condition as linguistic signs, even if distinct from other lexical elements.
\end{abstract}

Keywords: interjections; onomatopoeia; comics; mangas; German; Brazilian Portuguese

Resumo: Interjeições e onomatopéias recebem pouca atenção dentro dos estudos lingüísticos, e gramáticas e dicionários freqüentemente restringem-se a apresentar uma definição estereotipada e alguns poucos exemplos. Desprezadas pela literatura tradicional, essas expressões encontram seu "habitat natural" nas histórias em quadrinhos, nas quais se tornam elementos imprescindíveis da linguagem própria desse gênero textual. Este breve experimento sobre interjeições e onomatopéias presentes em mangás (histórias em quadrinhos japonesas) traduzidos para alemão e português mostra que, embora haja padrões fonéticos básicos comuns de acordo com o que representam (riso, passos etc.), as interjeições e onomatopéias da amostra diferem muito em ambas as línguas, o que ressalta sua condição de signos lingüísticos, mesmo que diferenciados em relação aos demais elementos do léxico.

Palavras-chave: interjeições; onomatopéias; histórias em quadrinhos; mangás; alemão; português do Brasil.

Zusammenfassung: Interjektionen und Onomatopöien wird sehr wenig Aufmerksamkeit von Sprachforschern geschenkt, und Grammatiken und Wörterbücher beschränken sich oft auf eine stereotypierte Definition und wenige Beispiele. Von der traditionellen Literatur verachtet, fanden solche Ausdrücke ihren wahren Platz im Comic und wurden zu unentbehrlichen Elementen dieses textuellen Codes. Dieses kleine Experiment mit ins Deutsche und brasilianische Portugiesisch übersetzten Mangas (japanischen Comics) zeigt, dass solche Elemente trotz gemeinsamer phonetischer Grundmuster je nach dargestelltem Ereignis (Schmerz, Lachen, Schritte usw.) große Unterschiede in beiden Sprachen aufweisen, was ihre Stellung als Sprachzeichen bestärkt, auch wenn sie sich von anderen Elementen des Lexikon differenzieren.

Stichwörter: Interjektionen; Onomatopöien; Comics; Manga; Deutsch; brasilianisches Portugiesisch

*Professora doutora do Departamento de Letras Modernas/FFLCH da Universidade de São Paulo selmamm@usp.br

Pandaemonium germanicum 11/2007, 157-188 - www.fflch.usp.br/dlm/alemao/pandaemoniumgermanicum 


\section{Introdução}

Embora quase todos nós saibamos o que são histórias em quadrinhos, ainda não há uma definição unânime e decisiva para elas. Contudo, se entendemos "linguagem" como um sistema de signos e regras, direcionado principalmente à comunicação humana, é indiscutível o fato de que elas representam uma linguagem característica.

O estudioso italiano de quadrinhos Daniele BARBIERI (cf. 1998) vê nelas uma interação entre estruturas gráficas, lingüísticas e narrativas. Podemos então dizer que os quadrinhos são uma linguagem que utiliza elementos gráficos e textuais, em maior ou menor proporção, combinando-os de maneira harmoniosa e indissolúvel.

Em qualquer linguagem, muito do que se percebe ou se comunica não está explícito. A linguagem dos quadrinhos, assim como a linguagem verbal, por exemplo, seleciona e apresenta símbolos concretos (seqüências de sons, letras ou palavras) que servem como "pistas" para que o receptor complete as informações a partir de suas experiências prévias, do seu conhecimento do mundo e da linguagem em questão. No caso de um conto, por exemplo, o escritor seleciona as palavras, construções sintáticas e estruturas narrativas que lhe pareçam mais apropriadas para atingir os seus objetivos estéticos. O mesmo vale para o autor de histórias em quadrinhos, que precisa utilizar, da forma mais efetiva, os elementos dos quais dispõe.

Temos aqui as bases do que Umberto ECO (cf. 2004: 144-150) denomina "semântica e sintaxe" dos quadrinhos: a semântica se revela através de diversos aspectos formais convencionais, válidos apenas dentro do universo dos quadrinhos, como o uso de balões, metáforas visuais, onomatopéias, a direção de leitura das seqüências de quadrinhos, ou enfim, o acordo tácito de que aquilo que ali está deve ser aceito e interpretado como uma seqüência narrativa. A sintaxe estaria nas relações entre os diversos quadros e na montagem dos elementos dentro deles.

Entre os elementos mais característicos dos quadrinhos estão as interjeições e onomatopéias, a visualização de sons paralingüísticos e ambientais que, assim como os efeitos sonoros do cinema, são indispensáveis para a elaboração da sua mensagem. Com pouca expressão na literatura tradicional, na qual se prioriza a descrição dos ruídos (como, por exemplo, em: "o telefone tocava" ou "um cão latia"), as onomatopéias encontraram seu "habitat natural" nas histórias em quadrinhos, onde assumem várias funções além de representar 
sons e ruídos: elas também podem criar um "fundo emocional", à semelhança da trilha sonora nos filmes, ou ainda servir como elemento de direcionamento da leitura.

A representação gráfica de sons e ruídos nos quadrinhos é essencial para a ambientação da trama e acabou por desenvolver características específicas, resultando num código próprio de leitura que mescla elementos icônicos e convencionais.

\section{Onomatopéias e interjeições nas histórias em quadrinhos}

Apesar de largamente utilizadas na linguagem oral cotidiana, a linguagem culta e escrita abomina onomatopéias, que estão quase completamente ausentes da literatura convencional, com algumas poucas exceções (entre as quais Ulysses de Joyce e narrativas de Wolfgang BORCHERT), apesar de encontradas em textos de canções (como em Wagner - cf. HAVLIK 1981: 7). Ao contrário do que acontece na literatura, nas histórias em quadrinhos as onomatopéias não são elementos raros e marginalizados, mas sim parte importante da linguagem, tanto que, hoje em dia, é praticamente impossível pensar em onomatopéias sem pensar em quadrinhos, e o mesmo é válido para as interjeições.

Encontram-se nas histórias em quadrinhos não apenas as onomatopéias "tradicionais", como as vozes dos animais e sons característicos de aparelhos, mas também e predominantemente ruídos que acompanham e sublinham a ação, emprestando-lhe uma maior dramaticidade. Principalmente devido às histórias em quadrinhos de super-heróis americanas temos aqui as já consagradas onomatopéias de socos, chutes e impactos diversos (pow, crash, bang), que passaram a fazer parte da linguagem falada de leitores do gênero e foram inteligentemente satirizadas e imortalizadas na série televisiva Batman da década de 1960.

A diversificação dos temas e da narrativa das histórias em quadrinhos levou à necessidade de reprodução de sons mais diversificados e à geração de novas onomatopéias,. Sons ambientais "naturais" como o do vento, água corrente, folhas farfalhando ou o barulho de aparelhos, máquinas e motores que nos circundam nas cidades passaram a ser representados de diversas formas, assim como são percebidos diferentemente em cada ocasião e em relação com o seu papel na trama, contribuindo para o que LEHMANN (1998) denomina "paisagens sonoras" (Klanglandschaften), que são tão social e culturalmente típicas e marcantes como qualquer paisagem visual. 
A onomatopéia em histórias em quadrinhos tem características que abrangem representação icônica, em termos da forma da grafia, e características grafêmicas, fonotáticas e fonéticas da língua em questão. Desse modo, as onomatopéias em histórias em quadrinhos podem ser vistas como elementos que integram o som, a língua e a imagem, devido a dois processos simultâneos de representação: a escrita e a gráfica, criando uma verdadeira "sintaxe" visual.

Ainda que os diferentes sons da natureza possam ser "objetivamente" fixados e analisados fisicamente, o ser humano, ao tentar reproduzir um determinado som, "filtra-o" através de uma percepção acústica moldada por sua língua. Um exemplo clássico são as várias onomatopéias para o canto do galo em diversas línguas, como por exemplo: cocoricó em português, kikeriki em alemão e cock-a-doodle-doo em inglês. Mesmo imaginando que os galos cantem de maneira diferente em diferentes países, o falante de uma determinada língua utilizará sempre a onomatopéia consagrada nessa língua para se referir a qualquer canto de galo "normal", ainda que ele possa distinguir acusticamente diferenças entre os vários indivíduos.

Assim, as onomatopéias não são totalmente icônicas no sentido de que buscam apenas reproduzir o som em questão. Essa parece ser a sua "raiz", como se pode perceber na criação de novas onomatopéias ainda não inteiramente consagradas e convencionalizadas, nas quais ainda se faz necessário recorrer ao material fonético. Contudo, quando uma onomatopéia se integra ao sistema da língua, ela passa a ser decodificada como qualquer outro lexema, como uma unidade lexical.

Outro filtro lingüístico que se aplica à "análise" dos sons para a criação de onomatopéias são as características de cada língua. Os sons são organizados em sílabas, como mostra o exemplo anterior do canto do galo, o qual é apresentado em quatro sílabas, no alemão e no português, ou em cinco, no caso do inglês, o que reforça a arbitrariedade da interpretação do material sonoro. $\mathrm{O}$ tamanho e a constituição das sílabas obedece geralmente ao sistema fonotático da língua. No entanto, a representação de ruídos obriga a algumas concessões, de modo que as onomatopéias freqüentemente apresentam combinações não usuais de fonemas, ou sílabas incomuns na língua em questão.

Nas histórias em quadrinhos, as características gráficas das letras usadas para grafar a onomatopéia são pertinentes à sua decodificação: a forma e tamanho das letras de uma onomatopéia são parte integrante de seu efeito no leitor, o que em alemão é denominado pelo termo "grafoestilístico" (graphostilistisch), referente a características gráficas pertinentes utilizadas na 
visualização de sons e emoções. Onomatopéias e interjeições são escritas normalmente em letras maiúsculas e o seu tamanho relativo indica o volume ou a intensidade do som. O local onde uma onomatopéia se encontra dentro da imagem é idêntico com o lugar e o momento onde ocorre o som ou ruído, tanto, que a onomatopéia chega a ser adaptada espacialmente ao som em duração e direção. Vários painéis podem ser ligados por uma onomatopéia, que se torna então um fator temporal.

Ainda são poucos os estudos lingüísticos dedicados às histórias em quadrinhos e, mais especificamente, às onomatopéias e interjeições nesse contexto. Uma das poucas publicações dedicadas inteiramente às onomatopéias em quadrinhos é o Lexikon der Onomatopöien (HAVLIK 1981). Em suas 263 páginas encontram-se, além de um extenso glossário de onomatopéias em língua alemã, inglesa e francesa, uma ótima introdução sobre sua forma e função em histórias em quadrinhos.

Em sua introdução, o Lexikon relembra que no início das histórias em quadrinhos texto e imagem eram separados, como se pode ver ainda hoje em séries como Tarzan ou Príncipe Valente. Com a introdução dos balões deu-se o passo decisivo para tornar os quadros acusticamente vivos, ao relacionar ótica e espacialmente as palavras àqueles que as proferiam. Conseqüentemente, precisou-se achar um meio de representar também ruídos na imagem. A fim de evitar a introdução de uma nova simbologia (como a usada para a notação musical), era necessário fazê-lo através da escrita convencional. Apesar de praticamente não haver limites para os autores de histórias em quadrinhos na criação de novas onomatopéias, um conjunto de regras próprias acabou se desenvolvendo, derivadas da escrita em cada língua e da sua integração com o desenho. Assim, para as onomatopéias e interjeições nas histórias em quadrinhos interessa menos a reprodução o mais realista possível do som do que o modo como tal representação deve ser expressa através da escrita (cf. HAVLIK 1981: 8ss).

Fora das histórias em quadrinhos, as onomatopéias e interjeições recebem muito pouca atenção dentro dos estudos da linguagem, sendo tratadas até mesmo "com desprezo" (stiefmütterlich), segundo KÜHN (1979: 289). As gramáticas e dicionários dedicam poucas linhas a elas, e parecem repetir uma mesma definição, a qual é, na maioria das vezes, reducionista, especialmente no caso das onomatopéias. As interjeições recebem um tratamento mais detalhado, mas ainda assim bastante vago. Vejamos agora alguns exemplos do tratamento dispensado às onomatopéias e interjeições em gramáticas e dicionários do 
alemão e do português do Brasil.

\section{Interjeições em dicionários e gramáticas brasileiros e alemães}

O Dicionário Honaiss (2002) define interjeição como:

palavra invariável ou sintagma que, com entonação peculiar, geralmente sem combinar-se gramaticalmente com elementos da oração, formam, por si sós, frases que exprimem uma emoção, uma sensação, uma ordem, um apelo ou descrevem um ruído (p.ex.: psiu!, oh!, coragem!, meu Deus!).

Em sua Moderna Gramática Portuguesa, Evanildo Bechara define interjeições como “[...] a expressão com que traduzimos os nossos estados emotivos" (BECHARA, 1999: 330). Apresenta também uma lista de 15 situações e as interjeições mais comuns para cada uma delas (ex.: de exclamação: viva!; de admiração: ah! ob!; de dor física: ai! ui!; de satisfação: upa! oba! opa! etc.).

Mattoso Câmara, em seu Dicionário de Lingüistica e Gramática, define interjeição como uma:

palavra que traduz, de um modo vivo, os estados d'alma. É uma verdadeira palavra-frase, pela qual o falante, impregnado de emoção, procura exprimir seu estado psíquico num momento súbito, em vez de se exprimir por uma frase logicamente organizada" (CÂMARA JR. 1977:147).

Matoso identifica três tipos de interjeições (cf. id.ib):

a) certos sons vocálicos, que na escrita se representam de uma maneira convencional fixa; ex.: ah! (onde a letra h em posição final marca uma aspiração pós-vocálica, que só aparece em português nesses casos)

b) verdadeiros vocábulos, já no domínio da língua; ex.: arre! - olá!;

c) uma locução interjetiva; ex.: ora bolas! - valha-me Deus!

O Dicionário de Lingüística de Dubois tem uma definição semelhante, incluindo várias classes de palavras:

Chama-se interjeição uma palavra invariável, isolada, que forma uma frase por si mesma [...] e que exprime uma reação afetiva viva: onomatopéias (ah, oh, etc.), substantivos, (céus, Deus, diacho), advérbios (bem, etc.), locuções adverbiais (ora bolas! valha-me Deus etc.). (DuboIs et alii 1998: 349)

Essa multiplicidade de classes de palavras dentro das interjeições é detalhada pelo Dicionário Honaiss, que afirma haver interjeições de vários tipos ou 'níveis' vocabulares: aquelas que ocorrem de modo mais ou menos espontâneo e que não derivam de outras palavras, e palavras cujo uso interjetivo é um desenvolvimento ou derivação do conteúdo semântico e da função 
sintática da palavra ou expressão de origem (p.ex., tomara $[<\mathrm{v}$. tomar $]$; oxalá - cf. HOUAISs 2002). Considerando apenas as interjeições não derivadas de outras palavras, é sugerida a seguinte subdivisão:

a) as que praticamente não apresentam caráter vocabular, por serem constituídas de sons inarticulados ou por seqüências de fonemas que não ocorrem em outras palavras. [ex. hm!

b) aquelas que apresentam sons articulados, com fonemas que fazem parte do sistema da língua ( $a i, e b a$, ei, epa, oba, opa, ui, xi etc.) e cujo caráter vocabular é mais definido, tendo uso bastante generalizado e convencionado, embora algumas guardem espontaneidade e expressividade bastante marcadas, como ai e ui (gritos de dor, excitação). Este tipo de interjeição. incorpora-se, de certo modo, ao repertório comunicativo da língua, passando a fazer parte do vocabulário desta [...] (id.)

Do lado alemão, não há grandes diferenças em relação ao apresentado em português.

Para o Duden Universalwörterbuch (2003), interjeições são enunciados sonoros semelhantes a palavras, geralmente sintaticamente isolados, com os quais se expressam sensações ou exortações ou se imitam sons. Também são chamadas Ausrufewort ou Empfindungswort, tendo como exemplos oh, pfui, pst, muh.

A Duden Grammatik (2005) apresenta onomatopéias e interjeições como duas subclasses das partículas. No caso das interjeições ou partículas expressivas, elas são definidas como a expressão de emoções espontâneas, reativas, ou de valoração de um conteúdo, podendo conter sons ou combinações de fones que não são comuns em outras palavras alemãs. Algumas podem, de acordo com a entoação, expressar diversas sensações e valorações.

Em sua Deutsche Grammatik, Ulrich Engel também contempla as interjeições entre as partículas e complementa o que já foi apresentado com a observação de que elas servem primeiramente à expressão de sensações corporais e estados de espírito e são freqüentemente imitativas de sons. Em vista disso, pergunta-se se as interjeições devem realmente ser consideradas como palavras alemãs, deixando, porém, a questão em aberto (ENGEL 1988: 773).

A questão de se as interjeições devem ou não ser consideradas como palavras, apontada por Engel, torna-se ainda mais aguda no caso das onomatopéias.

A origem da palavra onomatopéia está nas palavras gregas onoma (nome) e poëin, (criar), o que poderia ser traduzido literalmente como "criar nomes", sendo usada atualmente para denominar expressões que reproduzem sons e 
ruídos (HAVLIK, 1981: 7). No entanto, essa característica de reprodução de fenômenos sonoros se apresenta como um grande empecilho para a integração das onomatopéias no sistema lingüístico, por questionar uma de suas bases: a arbitrariedade do signo.

O Lexikon der Onomatopöien apresenta a questão de forma bastante clara:

Uma característica básica das palavras é a sua arbitrariedade. Isso significa que a relação entre a forma do signo, seu significado e o estado de coisas ao qual ele se refere é aleatória. [...] Da mera seqüência de sons não se depreende nenhuma ligação com o estado de coisas designado.

Agora, nas onomatopéias propriamente ditas há claramente uma ligação entre sua forma e seu referente, a qual é sempre um fenômeno acústico: a similaridade fonética! Em vista deste pressuposto, a arbitrariedade das onomatopéias é claramente restringida. [...] (cf. HAVLIK 1981: 39) ${ }^{1}$

Mesmo assim, observa que o dicionário DUDEN contém mais de 180 palavras que podem ser consideradas onomatopéias. Apesar da polêmica lingüística, a maioria das fontes consultadas considera as onomatopéias como unidades lexicais, embora com características diferenciadas.

O Duden - Universalwörterbuch define a onomatopéia (Onomatopoetikum) como uma palavra que imita ou representa o som, utilizando o adjetivo lautmalend (aproximadamente "pintar/desenhar com sons"). A palavra germânica para o processo de formações de tais palavras é Lautmalerei, definida como a reprodução de sons naturais ou assemelhados através de fones que soam de modo semelhante (cf. DUDEN 2003).

Como já mencionado, as gramáticas do alemão consideram onomatopéias como partículas. Para a Duden Grammatik, as onomatopéias são palavras representativas que servem primeiramente à imitação de sons e fenômenos sonoros de vários tipos, como o canto do galo: kikeriki., o latido do cachorro: wau, wau; wuf wuf, estouro ou tiro: peng, boing; relógio: ticktack etc. Observa ainda que em histórias em quadrinhos há um grande número de onomatopéias, geralmente pouco convencionalizadas, cuja função consiste menos na expressão de emoções do que na pura reprodução do som. Também faz menção à estrutura das onomatopéias, afirmando que elas podem ser - de acordo com a base sonora a ser imitada - estendidas, duplicadas ou reduplicadas (cf. DUDEN 2005: 606).

\footnotetext{
1 Eine Grundeigenschaft von Wörtern ist deren Arbitrarität. Darunter versteht man, dass die Zuordnung zwischen dem Zeichenkörper, dessen Bedeutung und dem Sachverhalt, auf den das Wort verweist, beliebig ist. [...] Aus der bloßen Lautfolge der Wörter ergibt sich kein Zusammenhang mit dem bezeichneten Sachverhalt. Nun existiert bei den eigentlichen Onpos sehr wobl ein solcher Zusammenhang zwischen Zeichenkörper und dem Sachverhalt, der hier stets eine akustische Erscheinung ist: die phonetische Ähnlichkeit! Durch diese Forderung wird die Arbitrarität der Onpos deutlich eingeschränkt. (HAVLIK 1981: 39 - todas as traduções de trechos citados são de minha autoria).
} 
Observa também que em histórias em quadrinhos há um grande número de onomatopéias, geralmente pouco convencionalizadas, cuja função consiste menos da expressão de emoções do que da pura reprodução do som. Também faz menção à estrutura das onomatopéias, afirmando que elas podem ser - de acordo com a base sonora a ser imitada - estendidas, duplicadas ou reduplicadas (id.).

O dicionário Honaiss observa que as onomatopéias são geralmente consideradas signos motivados, i.e., que têm relação objetiva - e não apenas arbitrária - com aquilo que significam (por evocação). O dicionário apresenta duas acepções para onomatopéia: a formação de uma palavra a partir da reprodução aproximada, com os recursos de que a língua dispõe, de um som natural a ela associado, e a palavra assim formada (p.ex.:pum, tiquetaque, atchim, chuá-chuá, zunzum etc.). Faz notar ainda que, embora sejam um recurso expressivo associado à linguagem, as onomatopéias diferenciam-se das interjeições por não traduzirem um estado emocional (cf. HOUAISS 2002).

Também Matoso Câmara salienta que na onomatopéia "não se trata de imitação fiel e direta do ruído, mas da sua interpretação aproximada com os meios que a língua fornece" (CÂMARA JR. 1953: 59). Matoso observa ainda que a estrutura fonológica das onomatopéias apresenta muitas vezes traços especiais: são em regra monossílabos, freqüentemente com reduplicação, acompanhada ou não de alternância vocálica; ex.: tique-taque, toque-toque (id.).

O dicionário Houaiss distingue entre onomatopéias não lingüisticas (aquelas que imitam ou procuram imitar, mais ou menos fielmente, os sons do mundo com o aparelho fonador, sem necessariamente articularem a emissão vocal da maneira usualmente empregada. na língua) e onomatopéias lingüisticas (integradas ao sistema fonológico, tendo por isso uma semelhança apenas aproximativa e histórica e culturalmente cambiante com os sons imitados). A obra sugere uma distinção semelhante entre representações gráficas de onomatopéias: há aquelas que seguem certas convenções ou regularidades ortográficas da língua (blém-blém; bibi-fonfom) e as usadas ou criadas ad hoc (o motor falhou: fffrttoct - cf. HOUAISS 2002).

O Dicionário de Lingüistica de Dubois também faz considerações sobre a integração das onomatopéias no léxico de uma língua:

a onomatopéia se integra no sistema fonológico da língua considerada; todos os fonemas de cocoricó, tique-taque, au-au são portugueses, mesmo se sua disposição difere um pouco das combinações mais freqüentes da língua. Além disso, a onomatopéia constitui uma unidade lingüística suscetível de um funcionamento em língua, marcada por um sistema de distribuição e de 
marcas: dir-se-ão uns cocoricós, um au-au agressivo; eventualmente, derivados serão possíveis: um neologismo cocoricar receberá facilmente uma interpretação semântica (DUBOIS et alii 1998: 442).

Dos dicionários e gramáticas citados, em ambas as línguas, a versão eletrônica do dicionário Honaiss é a que dedica mais espaço e apresenta maiores detalhes em relação às onomatopéias e interjeições. No entanto, encontra-se nessa obra o seguinte comentário:

[...] observa-se, em tempos recentes, uso de empréstimos ou adaptações de palavras onomatopaicas do inglês; esse tipo de influência, bem característico da relação entre cultura dominante e dominada, ocorre também na grafia [...], pois verifica-se principalmente em histórias em quadrinhos, meio que por excelência faz uso escrito de onomatopéias, e em arte pop. (HouAISS 2002)

Esta observação é muito pouco feliz, pois tenta reduzir um fato lingüístico a um viés sociológico. Como já mencionamos, antes das histórias em quadrinhos, o papel das onomatopéias era muito restrito, mas nelas, as onomatopéias são fundamentais para a ilusão de realidade de uma cena se desenrolando em tempo real em frente ao leitor. Desse modo, é compreensível que grande parte das onomatopéias atuais tenha sido motivada por seu uso em histórias em quadrinhos.

Considerando-se que as histórias em quadrinhos americanas, por diversas razões editoriais, foram por longo tempo as mais difundidas no mundo ocidental, é de se esperar que onomatopéias que não existiam no português fossem "importadas" do inglês, já que essa é a motivação de qualquer empréstimo lingüístico: denominar algo para o qual não havia previamente uma palavra na língua em questão. Assim, era de se esperar que tais onomatopéias fossem assimiladas a partir das histórias em quadrinhos americanas.

Se o simples empréstimo lingüístico caracterizasse uma relação de dominação, o fato de o Brasil ter assimilado palavras de origem africana ou indígena caracterizaria as culturas africana e indígena como dominantes, ou ainda, o empréstimo de palavras brasileiras em Portugal faria do Brasil uma cultura dominante em relação àquele país. Se esse claramente não é o caso, então, por que a assimilação de onomatopéias americanas denotaria uma relação "característica de cultura dominante e dominada"?

Observações como a do Houaiss refletem, a meu ver, um dos grandes entraves à pesquisa acadêmica das histórias em quadrinhos: ainda há vários preconceitos quanto a essa linguagem, sendo freqüentemente difícil distanciar-se de convicções pessoais e análise sócio-cultural e fixar-se apenas 
nos fenômenos próprios dessa linguagem. Felizmente, o estudo acadêmico das histórias em quadrinhos tem mostrado avanços significativos na última década.

Esse pequeno panorama das interjeições e onomatopéias em gramáticas e dicionários do alemão e do português nos permite chegar às seguintes conclusões preliminares:

1. Onomatopéias são expressões que espelham a relação entre sua forma e seu significado, através da similaridade fonética com o fenômeno acústico que as motivou. Esse traço é compartilhado com as interjeições sem caráter vocabular, ou seja, que não são derivadas de palavras já existentes na língua.

2. Contudo, enquanto as interjeições são expressões de um estado de espírito do falante que as emitiu, podendo consistir tanto de sons inarticulados como de palavras já existentes na língua em questão, as onomatopéias são resultado de um processo de representação de sons de natureza diversa através dos fones de uma língua, reproduzindo-os e integrando-os à linguagem oral ou escrita.

3. Enquanto as interjeições são freqüentemente reconhecidas como parte do sistema de uma determinada língua, as onomatopéias são geralmente vistas como soluções ad hoc e/ou empréstimos ligados a um contexto específico, neste caso, as histórias em quadrinhos.

Do ponto de vista de seu significado, as possibilidades de utilização de interjeições e onomatopéias são muito maiores em relação às palavras convencionais. O Lexikon der Onomatopöien, por exemplo, apresenta uma grande quantidade de expressões diversas de sentido semelhante, ou ainda, de expressões semelhantes com sentidos diversos. Contudo, não é possível intercambiar livremente todas as onomatopéias. A expressão PFFT, por exemplo, seria tão inadequada para expressar a batida de um gongo quanto DONG para um gás escapando (cf. HAVLIK 1981: 39).

\section{Interjeições e onomatopéias em alemão e português}

Talvez o mais importante estudo específico sobre onomatopéias em português e alemão em contraste até o momento seja o de Erwin KOLLER (2003), que faz um levantamento de interjeições e onomatopéias em dicionários e gramáticas alemães e portugueses.

Assim como Bechara, Koller considera as interjeições como o termo 
genérico, englobando as onomatopéias, e parte do pressuposto de que elas têm valor de um enunciado (p.175), classificando-as, com base em Bühler e Jakobson, de acordo com sua função comunicativa dominante. A primeira grande divisão proposta por Koller é entre interjeições que têm função predominantemente representativa (Darstellungsfunktion), de apelo (Appelfunktion), expressiva (Ausdrucksfunktion), fática, metalingüística e poética.

Dentre as interjeições com função de representação, observa que, apesar de algumas poucas serem completamente arbitrárias (como "bingo”!), a grande maioria é "motivada onomatopaicamente", procurando mimetizar elementos acústicos ou mesmo ópticos dos acontecimentos aos quais se referem. A partir dos exemplos apresentados, vê-se que estas interjeições são o que comumente se entende por "onomatopéias", termo que será mantido neste artigo para tais expressões (cf. KOLLER 2003: 177).

Especialmente interessante é a apresentação do que Koller denomina interjeições "óptico-miméticas", como "zás", em português, ou "zack", em alemão, e que são bastante freqüentes nos quadrinhos. Segundo ele, tais interjeições "se encontram em uma relação virtualmente mimética com as onomatopéias acústicas, na medida em que os movimentos rápidos denominados por elas são ligados a ruídos" (cf. op.cit., p.176s.). No Honaiss (2002) elas são denominadas palavras expressivas, “[...] aquelas cujo emprego não é apenas de caráter imitativo, mas evoca vivamente o modo como uma ação ou processo se dá (qás, tchã , pimba, vapt-vupt) [...]”.

As onomatopéias acústico-miméticas, mais próximas do protótipo de onomatopéias como elementos representativos de sons, são organizadas por Koller a partir do ser ou objeto causador do som, seja ele um ser humano, um animal ou um objeto/instrumento, apresentando exemplos como hm!/fum!, iab!/ bim!, king!/dlim!, bum!/ bum! (cf. KOLLER 2003: 177).

As interjeições com função expressiva são aquelas que os dicionários e as gramáticas geralmente apresentam como "interjeições" propriamente ditas, e serão aqui assim denominadas. Koller divide-as entre expressões de sentimentos (Gefüblsausdrücke), de atitude (Einstellungsausdrücke) e "palavras de sensações" ("Empfindungswörter").

O estudo de Koller apresenta vários exemplos em contraste nas duas línguas em questão e uma taxonomia bastante ilustrativa das muitas possibilidades expressivas desses elementos pouco explorados pelos lingüistas. O estudo contempla apenas obras portuguesas, o que faz com que muitas interjeições apresentadas sejam desconhecidas ou pouco utilizadas no Brasil. 
Além disso, por se restringir a dicionários e gramáticas, apresenta também um número bastante restrito de interjeições em ambas as línguas, quando se consideram as possibilidades encontradas nas histórias em quadrinhos. Por exemplo, Koller não encontra, nas obras portuguesas consultadas, um correspondente para a interjeição haha! do alemão, representando uma risada (cf. op. cit. p. 175), que pode, no entanto, ser facilmente encontrada em qualquer exemplar de histórias em quadrinhos no Brasil. De qualquer forma, o estudo representa um importante passo na pesquisa contrastiva das interjeições e onomatopéias nas duas línguas em questão.

Entre as funções levantadas por Koller, duas em especial - as de representação e de expressão - representam a grande maioria das interjeições / onomatopéias presentes nas histórias em quadrinhos. Por esta razão, vou me restringir a elas neste artigo, onde pretendo apresentar, como introdução ao tema, alguns exemplos retirados de um pequeno corpus de onomatopéias e interjeições em mangás (histórias em quadrinhos japonesas) traduzidos para o alemão e para o português. Vale ressaltar que o estudo tem caráter exploratório, sem pretender chegar a resultados conclusivos.

\section{Onomatopéias e interjeições em mangás traduzidos para o alemão e para o português}

A escolha por histórias em quadrinhos japonesas e não originais alemãs ou brasileiras baseia-se em três considerações:

a) a busca de um tertium comparationis, ou seja, um elemento neutro que unisse as duas amostras, a alemã e a brasileira. Como as histórias em quadrinhos alemãs e brasileiras diferem muito em seus temas e soluções gráficas e lingüísticas, o uso de uma terceira tradição quadrinística asseguraria uma maior homogeneidade;

b) uma maior ocorrência de onomatopéias e interjeições em mangás, quando comparados às histórias em quadrinhos ocidentais, devido a uma maior integração entre texto, imagem e onomatopéias e interjeições na condução da narrativa;

c) a necessidade, em vista da grande diferença entre as línguas de partida e de chegada, de os tradutores adaptarem as onomatopéias japonesas (muitas das quais não existem em histórias em quadrinhos ocidentais), propiciando a criação de novas soluções. 
Vejamos, como exemplo, as interjeições e onomatopéias constantes de duas páginas da série Rurouni Kenshin (japonês), traduzidas para o português do Brasil, com o nome de Samurai X, e para o alemão, com o título Kenshin:

Rurouni Kenshin (japonês - vol. 15, p. 36-37):

doon doon (explosão); chikusho! (interjeição); haa (ofegante); gu ... (cerrando o punho); ga! (determinação).

Kenshin (alemão - p. 36-37):

shkla bawa (explosão); Mist. (interjeição); hub / ha! (ofegante); woop... (cerrando o punho); kla! (determinação).

Samurai $\boldsymbol{X}$ (português - p. 38-39):

boom! (explosão); droga! (interjeição); puf (ofegante); tchg... (cerrando o punho); tchkek (determinação).

(WATSUKI 1997 etc.)

Nota-se que parece não haver nenhuma correspondência entre as expressões nas três línguas, pelo menos no que se refere a estes exemplos específicos. Além disso, podemos perceber uma outra característica dos mangás: o uso de onomatopéias não apenas para reproduzir sons "reais" do ambiente ou da ação, mas também para criar efeitos dramáticos, como nos exemplos referentes a "cerrar os punhos" ou "mostrar determinação", que se encaixam no que Koller denomina interjeições óptico-miméticas. Tais onomatopéias são altamente desafiadoras para os tradutores, já que muitas vezes não há uma tradição de associar um efeito sonoro a tais ações ou atitudes em uma determinada língua. É importante ressaltar, no entanto, que não se trata aqui de investigar as traduções ou as considerações que as motivaram, mas apenas de utilizar as características dos mangás para motivar um grande número de ocorrências de onomatopéias e interjeições em ambas as línguas em foco.

No que se refere às onomatopéias e interjeições especificamente em histórias em quadrinhos, o Lexikon der Onomatopöien levanta várias considerações que são válidas, em grande parte, também para o português. A obra afirma que provavelmente as onomatopéias e interjeições mais conhecidas em alemão são aquelas das histórias em quadrinhos da Disney (HAvLIK 1981: 24), o que se deve em grande parte às ótimas traduções realizadas por Erika Fuchs para o alemão, ainda hoje objeto de estudos. Gráfica e semanticamente simples, as interjeições e onomatopéias Disney restringem-se em número a relativamente poucas, mas se repetem com freqüência. Mesmo as expressões originais americanas tornaram-se correntes em alemão e em várias outras línguas, como thud, blam, splash, zoom (id.). 
Uma outra observação bastante interessante e específica das onomatopéias em histórias em quadrinhos é a sua divisão em dois grandes grupos quanto à sua constituição: as onomatopéias propriamente ditas e as onomatopéias descritivas (umschreibend). Enquanto nas onomatopéias propriamente ditas tenta-se reproduzir o mais fielmente possível um som ou ruído, as onomatopéias descritivas permanecem ligadas à sua origem lingüística. Alguns exemplos de pares de mesmo significado ilustram a diferença (cf. HAVLIK 1981: 38):

$\begin{array}{lll}\text { Onomatopéias descritivas } & & \\ \text { BUAAAA } & \text { - HEUL } & \text { (uivar, chorar) } \\ \text { IIIEEEH } & \text { - KREISCH } & \text { (guinchar, gritar) } \\ \text { RRRCH } & \text { - SCHNARCH } & \text { (roncar) } \\ \text { BZZZ } & \text { - SUMM } & \text { (zumbir) } \\ \text { RRRGGGRRRRWWWWW } & \text { - KNURR } & \text { (rosnar) } \\ \text { PSSSSSCHT } & \text { - SPRITZ, ZISCH } & \text { (borrifar, sibilar) }\end{array}$

As onomatopéias descritivas em alemão utilizam geralmente o radical de verbos, principalmente daqueles que expressam ruídos ou produção de ruídos (KLIRR, SURR, ZISCH). Em português, esse tipo de onomatopéia parece ser menos freqüente que em alemão, mas também pode ser encontrada, como no caso de SOC, para representar um soco.

O Lexikon classifica ainda as onomatopéias e interjeições por temas, observando, ao final da Introdução, que as onomatopéias levantadas espelham a temática das histórias em quadrinhos, sendo os doze temas que apresentam a maior variedade de onomatopéias ligados, com apenas duas exceções, ao conceito geral "violência" (cf. HAVLIK 1981: 44):

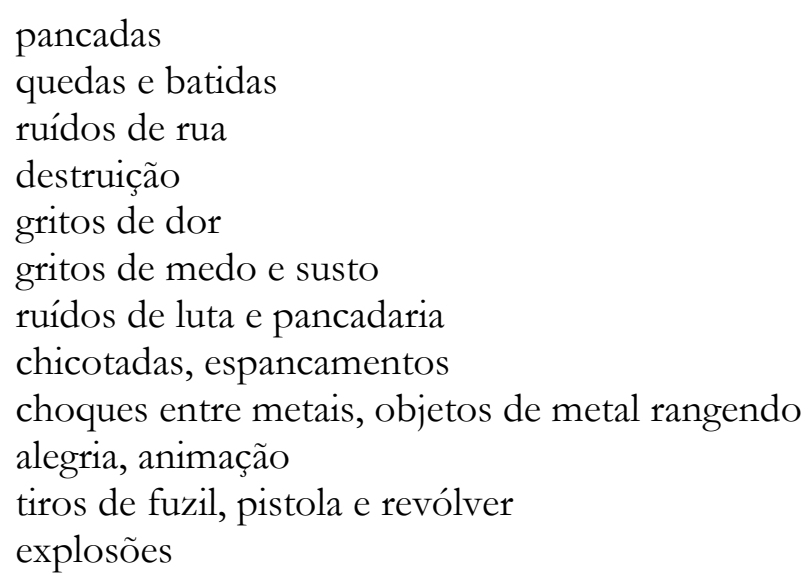

É importante notar que este resultado está diretamente ligado ao tipo de histórias em quadrinhos analisadas: como a grande maioria dos quadrinhos na Europa e nas Américas é constituída de histórias de ação lidas por jovens do 
sexo masculino, é de se esperar que esses temas predominem. Uma amostra de histórias em quadrinhos de outros gêneros ou públicos, como, por exemplo, obras de temática religiosa indianas ou histórias em quadrinhos femininas japonesas, certamente teria resultados diferentes destes. Embora o Lexikon se abstenha de comentários valorativos, é sempre necessário manter o distanciamento e a imparcialidade com relação aos resultados desse tipo de levantamento.

Neste artigo, são analisados exemplos de interjeições e onomatopéias com função de representação e expressão, segundo a classificação de Koller, denominadas aqui, respectivamente, onomatopéias e interjeições . Para cada uma delas, vou me restringir a três tipos de situações bastante comuns em histórias em quadrinhos de ação, a saber:

- interjeições: surpresa, dor e risos

- onomatopéias: passos, chutes, ruído ambiente (vento).

A seguir, são apresentadas as interjeições e onomatopéias encontradas em um levantamento de oito mangás brasileiros e sete alemães, em um total de 2628 páginas. As ocorrências são agrupadas, primeiramente, de acordo com as letras que as compõem, a entoação (representada pela pontuação: !, ?, ...), a duração (representada pela repetição das letras) e a presença de aspiração (representada pela letra " $H$ "). A segunda listagem apresenta as interjeições agrupadas "foneticamente", incluindo a aspiração. Em negrito estão destacadas as ocorrências presentes ou foneticamente similares nas duas línguas ${ }^{2}$.

\section{Interjeições}

\section{a) Surpresa}

\section{Alemão:}

AH / AH! / AAH / AAH! / AHH! / AHH... /AAHHH! / AAAH! AAAAH! / AAAAAAH!! / AHAAAA /ARGH! / Ä̈̈̈̈H! / GYAAH / HA / HA! / HA... / HA? / HA?! /HAH

\section{Português:}

\footnotetext{
...AH? / AAAH! / AAAH!! / AAAHHH! / AAH!! /AH / AH! / AH... /

${ }^{2}$ Utiliza-se aqui o termo "fonético" em um sentido bastante amplo, de apontar uma relação entre os sons representados e as letras utilizadas para esse fim. O termo "fonema" é usado para um som constante do sistema das línguas em questão, que pode ser grafado de diferentes formas, como, por exemplo, SCH em alemão e SH ou $\mathrm{CH}$ em português.
} 
AH...! / AH...!? / AHH... / AHN!? / AI AI AI AI / AW! EI! / EI!! / EI!!! / EPA! / EPA? / GASP... / GLUP! / GUAAA!?! / HA...?! / HA?! / HÃ? / HÃÃ?? / HUH...! / HUM? / O QUÊ?! / OH! / OH!! / OH...! / OOH! / OOOH!! / OPA! / OPS! / UAAAH! / UNGH! / UOOH...!

Organizadas foneticamente:

Alemão: AH - AHA - ARGH - ÄH - GYAH - HA - HAH

Português: AH - AHN - AI - AW - EI - EPA - GASP - GLUP - GUA - HA - HÃ

- HUH - HUM - O QUE - OH - OPA - OPS - UAH - UNGH - UOH

Temos aqui, em ambas as línguas, a predominância da vogal A (86\% em alemão e $50 \%$ em português). Em alemão, as únicas outras são a vogal Ä e a semivogal Y (no ditongo YA), enquanto o português utiliza todas as demais vogais orais (sendo que a vogal I aparece apenas nos ditongos AI e EI), a vogal nasal Ã e também o ditongo AW, provavelmente por influência do inglês.

Quanto às possibilidades fonéticas, é interessante ressaltar que há apenas dois exemplos de interjeições encontradas nas duas línguas: AH e HA, ou seja, a vogal A precedida ou seguida de aspiração, o que seria o "som" mais básico causado pela expulsão súbita do ar dos pulmões, em situações de surpresa. No alemão, a maioria das ocorrências (63\%) termina com aspiração, mas no português isso é bem mais raro (30\%). Enquanto no alemão todos os exemplos terminam em sílaba aberta, seguida ou não de aspiração, no português temos ainda a possibilidade de sílaba terminada por nasal (HUM), plosiva surda (GASP, GLUP) e africada (OPS).

As aspirações, a plosiva e a africada reproduzem o som resultante da respiração sendo liberada ou presa abruptamente, como acontece em situações de surpresa. Assim, podemos verificar que os fonemas utilizados e sua seqüência não são aleatórios, mas sim procuram reproduzir as características sonoras do evento em questão.

Nas duas línguas, verifica-se a repetição ou multiplicação da vogal e / ou da aspiração para prolongar o som, exprimindo, assim, o grau de surpresa (ou mesmo de susto) do momento. Outra característica destas ocorrências é a forte presença da pontuação, por vezes combinando vários sinais (exclamação, interrogação, reticências), também para modular a intensidade da surpresa ou os sentimentos que a acompanham (medo, confusão, admiração).

Em português, temos a ocorrência de interjeições já lexicalizadas (cf. HoUAISS 2002; CÂMARA JR. 1977: 147; BECHARA 1999: 330s.), como (O) QUÊ, 
OPA, enquanto que em alemão foram encontradas apenas interjeições não lexicalizadas.

\section{b) Dor}

\section{Alemão:}

AAH / AAAAAAAAH!! / AAARGH! / ARRGH! / ARGH! / AU / AU! / AU!! / AUA / AUA! / AUA... / AUAA! / AUAAA... / AUTSCH / AUTSCH! / Ӓ̈̈CHZ / ÄCHZ / GUWAH / GUAAH / GUAAAH... / HAA / HAA! / HAA!! / KYAAH! / OOH / UAAAAH / UAAAAH! / UAAAAH!! / UWAAAAAH / UWAH / YAAH

\section{Português:}

AI! / AI...! / AIII... / AI AI AI AI!! / AI, AI, AAI! / ARGHH!! / AW! / GHНHНААА... / GUAAA!?! / GWAAH...! / GWAAAH! / GWAAAAOOOOOAAAAH! / IAAAUUU!!! / KYAAAAA... / OOH! / OUCH! / UAAAAAAH!! / UAAAAH... / UAAAH! / UAAAH...! / UAAARGH!!! / UÁÁRGH! / UGHHH!... / UH! / UH!... / UH...! / UH... / ...UH! / UH...!! / UI! / UI... / UII... / UOOH...! / URGH! / URGH!! / WAAAAAAH...!!

Organizadas foneticamente:

Alemão: AH - ARGH - AU - AUA - AUTSCH - ÄCHZ - GUWAH - GUAH HA - KYAH - OH - UAH - UWAH - YAH

Português: AI - ARGH - AW - GHA - GUA - GWAOAH - GWAH - IAU - KYA - OH - OUCH - UA - HUARGH - UÁRGH - UGH - UH - UI - UOH - URGH - WAH

Novamente nota-se, em alemão, a predominância da vogal A, presente em doze das catorze formas encontradas, sozinha como núcleo de sílaba ou nos ditongos YA, AU e WA. Encontram-se ainda exemplos das vogais Ä, O e U, mas não de E e I. No português, a vogal A também está presente em $65 \%$ das ocorrências, inclusive nos ditongos AI, IA, UA, YA e WA. As vogais I, O e U e os ditongos OU e UI também estão representados, não havendo ocorrências com a vogal E.

Também aqui a aspiração final está presente na maioria das ocorrências em alemão (57\%) e em 45\% das ocorrências em português. Tanto em português como em alemão, encontram-se exemplos de sílaba terminada por plosiva velar 
sonora + aspiração (ARGH, UGH, URGH) e de interjeições terminadas em africadas (AUTSCH, ÄCHZ, OUCH). Neste item não se encontram plosivas finais, que interrompem a respiração, mas sim, novamente, há uma reprodução da respiração liberada subitamente através da boca, com aspiração ou estreitamento da passagem do ar no espasmo da dor.

Temos, nesta situação, uma maior ocorrência de interjeições iguais ou semelhantes em ambas as línguas: ARGH - AU - AW - GUAH - GUA GWAH - KYA - KYAH - OH - UA - UAH - WAH. É interessante ressaltar que as interjeições terminadas em GH e africadas são muito semelhantes e podem ter sido baseadas em onomatopéias do inglês, enquanto os exemplos KYA / GYA / GUA estão presentes também nos originais em japonês.

\section{c) Risos}

\section{Alemão:}

HA HA / HA HA HA / HAHAHA / HAHAHAHAHA / HE HE / HE HE HE / HEHE / HEHEHE / HI HI / HI HI HI / HIHI! / HIHIHI / NYAHAHAHA / RAA / WUHAHA

\section{Português:}

AHAHA / AH AH AH / AH AH AHA / AH HÁ, HÁ. / HÁ!!! / BUA, HA, HA, HA, HA! / EH, EH! / EH EH EH / GAH, HA, HA, HA, HA! / HA HA HA / HA HA HA! / HA,HA, HA, HA! / HAHAHAHA!!! / HE, HE. / HE, HE, HE. / HEH / HEHEHE / HEHEHEHEHUEHUE / HEHEHUEHUEHUE / HI HI / HI HI HI! / HI HI HI HI / HU HUÁ HUÁ HUÁ / HU, HU / HU, HU! / HU, HU, HU... / HU, HU. / HU HU HU. / HU, HU... / HUA, HA HA, HA, HA! / HUI / IH IH IH IH / IH, IH! / OHOHO... / QUÁ QUÁ QUÁ QUÁ! / RÉ, RÉ, RÉ, RÉ!

Organizadas foneticamente:

Alemão: HA HA - HA HA HA - HE HE - HE HE HE - HI HI - HI HI HI - NYAHAHAHA - RAA - WUHAHA

Português: AH AH AH - AH AH AHA - AH HÁ, HÁ - HÁ - BUA, HA, HA, HA, HA! - EH EH EH - GAH, HA, HA, HA, HA! - HA HA HA - HE, HE HEH - HEHEHE - HI HI - HI HI HI - HU HUÁ HUÁ HUÁ - HU, HU HU, HU, HU... - HUA, HA HA, HA, HA! - IH IH IH IH - OHOHO - QUÁ QUÁ QUÁ QUÁ! - RÉ, RÉ, RÉ, RÉ! 
Tanto em alemão como em português, a maioria das ocorrências é iniciada por aspiração. No alemão, há ainda uma ocorrência iniciada por nasal (NYAHAHAHA), uma por vibrante (RAA) e uma por um ditongo não pertencente ao sistema do alemão (WUHAHA). Em português, além do início por aspiração ou vogal, há também interjeições iniciadas por plosiva (BUA, HA, HA, HA, HA!; GAH, HA, HA, HA, HA!; QUÁ QUÁ QUÁ QUÁ!) e vibrante (RÉ, RÉ, RÉ, RÉ!). Em ambas as línguas, todas as ocorrências terminam em sílaba aberta, sendo que no alemão não há exemplos de aspiração final, que, no entanto, aparece em duas ocorrências do português (IH IH IH IH e HEH).

Nota-se também a presença clara de várias sílabas, que podem ser escritas juntas ou separadas, inclusive por vírgulas. A intermitência destas interjeições, com grande ocorrência de aspirações no início das sílabas, reproduz a liberação do ar em rajadas sucessivas, típica do riso. Não há casos de multiplicação simples de vogais ou aspirações para indicar a duração do evento, como nas interjeições anteriores, mas de sílabas: quanto mais longo o riso, maior o número de sílabas.

Aqui se encontra em ambas as línguas uma maior diversidade das vogais utilizadas, embora a vogal A continue tendo a primazia (56\% em alemão e 50\% em português). Em alemão, as vogais I e E aparecem com maior destaque do que nas outras situações e ainda há exemplos com os ditongos YA e WU. Em português, novamente há ocorrência de todas as vogais (embora $\mathrm{O}$ só apareça em um exemplo) e do ditongo UA. É interessante notar que, muito freqüentemente, as interjeições apresentam uma sílaba inicial diferente daquelas que se seguem. Essa sílaba inicial corresponde a uma fase inicial na qual "se toma fôlego" suficiente para depois irromper em uma risada, geralmente ruidosa. Note-se que os exemplos que apresentam essa sílaba inicial estão sempre entre os mais longos (WUHAHA; NYAHAHAHA; BUA, HA, HA, HA, HA!; GAH, HA, HA, HA, HA!; HU HUÁ HUÁ HUÁ; HUA, HA HA, HA, HA!).

Nesta situação, há novamente coincidências entre as duas línguas, em interjeições formadas por aspiração + vogal: HA (HA); HE (HE); HI (HI). Essas ocorrências correspondem à metade das possibilidades encontradas para o alemão, mas apenas a $20 \%$ das possibilidades encontradas em português. 


\section{Considerações gerais}

No que tange às interjeições presentes no corpus, de modo geral, podemos notar em ambas as línguas a preponderância de vogais (principalmente da vogal A), com ou sem aspiração. Matoso lembra que as interjeições são o único caso de aspiração em posição final no português do Brasil (cf. CÂMARA JR. 1977: 147). Provavelmente o mesmo ocorre também no alemão. Uma hipótese para a preponderância de vogais pode ser o fato de que interjeições exprimem estados de espírito, expressos mais facilmente por vocalizações, já que estas permitem modulação tonal e de duração, aumentando as possibilidades de expressão de nuances dos sentimentos. Isto é reforçado pela grande presença de pontuação expressiva (..., ?, !), praticamente ausente em onomatopéias encontradas na amostra.

Nota-se aqui, em geral, uma maior diversidade de formas no português, especialmente no caso do riso, o que poderia ter resultado do fato de os mangás examinados para cada língua não terem sido sempre os mesmos. No entanto, seria estranho que essa fosse a única razão para a disparidade: seria necessário que, coincidentemente, todos os mangás brasileiros examinados apresentassem muito mais situações que exigissem o uso de interjeições do que os alemães constantes da amostra, o que é pouco provável.

Para sanar essa dúvida, foi examinada uma subamostra de dois mangás correspondentes, em português e em alemão. Encontramos um total de 7 interjeições distintas em alemão e 9 em português para surpresa; 9 em alemão e $9 \mathrm{em}$ português para dor, e, para risos, $6 \mathrm{em}$ alemão contra $10 \mathrm{em}$ português. Isso reflete os resultados gerais apresentados anteriormente, em que há menor diferença entre as duas línguas no caso de interjeições de dor, ampliando-se na surpresa e no riso. Podemos, portanto, levantar a hipótese de que há, em português, uma maior variedade de interjeições possíveis, ao menos para esses três tipos de situações. Contudo, a amostra é muito reduzida e não é equivalente para ambas as línguas, de modo que não é possível obter qualquer resultado estatístico definitivo.

Apesar de haver formas presentes em ambas as línguas, nota-se que elas são uma minoria. Mesmo nos casos em que uma língua apresenta muito maior variedade de formas que a outra (como no riso), não se observa que todas ou grande parte das possibilidades da língua com menos variedade estejam presentes na outra língua, o que mostra que cada língua tem sua interpretação para os sons a serem representados através da escrita. 
É de se observar aqui que, enquanto o português utiliza quase todas as vogais em todos os três temas abordados (apenas "E" não é usado na situação de dor), no alemão há grande primazia da vogal "A", secundada por "U"/"W" (com exceção do riso, no qual "E" e "I" são bastante representativas). Talvez o uso de todas as vogais em português, aliado à presença da nasalidade (inexistente nas ocorrências em alemão), seja responsável pelo desequilíbrio da variedade de formas encontradas entre as duas línguas nestas interjeições. Também é interessante notar que não há, nas interjeições de riso em alemão, qualquer exemplo de aspiração final, ao contrário do que acontece em português.

Embora a imensa maioria seja de interjeições não lingüísticas, em português encontram-se exemplos lexicalizados como (O) QUÊ, OPA (surpresa), enquanto em alemão temos uma ocorrência de interjeição descritiva: ÄCHZ, derivada do verbo ächzen ("gemer”). Encontramos ainda, em ambas as línguas, formas que podem ter sido importadas do inglês, como GASP, GWAH, GLUP, ARGH e OUCH, além de KYA / GYAH e BUAHAHA, presentes nos originais japoneses.

\section{Onomatopéias: passos, chutes e ruído ambiente}

A seguir, estão listadas as onomatopéias encontradas para cada uma dessas situações. As formas entre parênteses na segunda listagem indicam a possibilidade de reduplicação:

\section{a) Passos}

Alemão:

TAC / TAC TAC / TAC! TAC! TAC! / TAP / TAP! TAP! / TCHAC / TCHAC TCHAC / TEC TEC / TEC TEC TEC TEC / TOC TOC TOC / TUMP

Português:

KOCK KOCK KOCK / KTAK KTAK / TAP / TAPTAP / TAP TAP / TAP TAP TAP / TOCKA TOCKA / TOK TOK

Organizadas foneticamente:

Alemão: TAC (TAC) / TAP (TAP) / TCHAC (TCHAC) / TEC (TEC) / TOC (TOC) / TUMP 


\section{Português: KOCK (KOCK) / KTAK (KTAK) / TAP (TAP) / TOCKA (TOCKA) / TOK (TOK)}

Nestas onomatopéias, ao contrário do que acontecia anteriormente nas interjeições, o alemão apresenta uma maior variedade de vogais: em português, temos apenas as vogais $\mathrm{A}$ e $\mathrm{O}$, enquanto em alemão apenas a vogal I não está representada. A vogal A continua apresentando a maior freqüência em alemão (63\%), enquanto em português há um equilíbrio entre A e O. Há apenas duas formas comuns a ambas as línguas e o alemão apresenta uma possibilidade a mais do que o português.

Em ambas as línguas, observa-se que praticamente todas as ocorrências (com exceção de TOCKA) iniciam-se e terminam por plosivas surdas. O padrão predominante é plosiva surda + vogal + plosiva surda, com 63,5\% de todas as ocorrências (TAC; TAP; TEC; TOC/TOK; KOCK). No caso de TCHAC, temos uma pequena variação desse padrão, com início por africada (fonema formado por plosiva + fricativa). As ocorrências que fogem ao padrão são TUMP, com a introdução de uma nasal após a vogal, KTAK, com duas plosivas surdas antes da vogal, e TOCKA, com vogal final formando uma segunda sílaba.

Esse padrão representa uma pancada, um som seco, breve, que cessa subitamente. Nas onomatopéias, as vogais são responsáveis pelo timbre do som a ser representado (pancada mais ou menos surda) e varia de acordo com os elementos que o produzem na situação a ser representada. No caso de passos, um dos elementos é sempre o pé, que, no entanto, pode estar descalço, calçado com sapatos de salto ou de sola macia etc. Por outro lado, o material da superfície sobre a qual se caminha também influencia a vogal a ser utilizada: assoalho de madeira, pedra, tatami (esteiras de palha japonesas), chão de terra. A relação entre a vogal utilizada e os materiais envolvidos no som a ser reproduzido mereceria um estudo próprio e não será abordada neste artigo, mas pode-se perceber que TUMP sugere um som mais surdo do que, por exemplo, TEC, fazendo-nos pensar em impactos do pé com materiais diferentes em cada exemplo.

Temos aqui também a possibilidade de reduplicação, representando o caminhar, ou seja, passos sucessivos. As formas KTAK e TOCKA sugerem um som "duplo" (K-TAK; TO-CKA), que talvez seja uma representação do impacto do calcanhar, o primeiro ponto do pé a tocar o chão, seguido do impacto da sola do pé, completando o passo. 


\section{b) Chutes}

Alemão:

BADONK / BA-DUSCH / BAM BAM / BAMM / BOM / KLACK / KRACH / KRACK / PENG / TRAMPEL TRAMPEL / TSCHANK / TUMP / ZA-DUSCH

\section{Português:}

BONC / BONK! / BOOOC / DUNC DUNC / POF / TUM!

Organizadas foneticamente:

Alemão: BADONK / BA-DUSCH / BAM (BAM) / BAMM / BOM / KLACK / KRACH / KRACK / PENG / TRAMPEL (TRAMPEL) / TSCHANK / TUMP / ZA-DUSCH

Português: BONC / BONK! / BOOOC / DUNC DUNC / POF / TUM!

Nas onomatopéias referentes a chutes, nota-se uma grande diferença na variedade de formas entre as duas línguas, sendo que o alemão apresenta mais que o dobro de formas do que o português. Novamente, o alemão utiliza mais vogais do que o português: este último apresenta apenas onomatopéias com $\mathrm{O}$ e U, enquanto no alemão apenas não está presente a vogal I.

No português, nota-se um padrão bastante semelhante ao encontrado nos passos, com plosivas iniciando e finalizando as onomatopéias dos chutes. No entanto, ao invés de apenas uma vogal, tem-se o padrão vogal + nasal como o mais freqüente (BONC; BONK; DUNC; TUM). Dentre as plosivas iniciais, a maioria é de sonoras, especialmente a plosiva B. Todas as plosivas finais são surdas, sendo que se encontra ainda uma ocorrência terminada por fricativa (POF) e outra por nasal (TUM).

No alemão, as plosivas também são dominantes em posição inicial (69\%), porém, com predominância de surdas. Se considerarmos que as fricativas são formadas por uma plosiva + fricativa e que nas onomatopéias "duplas" (BA(-)DONK; BA(-)DUSCH; ZA(-)DUSCH) o segundo elemento é o que realmente representa o impacto, podemos considerar que há sempre o início por plosiva em todas as ocorrências. Esse parece ser o único padrão para todas as ocorrências em alemão. A posição final é novamente ocupada majoritariamente por plosivas surdas, mas também há ocorrências de final em nasal e em fricativa. 
Em TRAMPEL (TRAMPEL), temos uma ocorrência de onomatopéia descritiva, sendo derivada do verbo trampeln ("pisar", "patear"). Esta onomatopéia apresenta um caminho interessante, já que o verbo tem igualmente origem onomatopaica. Assim, esta ocorrência não é motivada diretamente por um som a ser representado, mas está muito mais próxima do signo lingüístico convencional, pois, para decodificá-la, é necessário recorrer ao conhecimento da língua alemã, ao contrário de onomatopéias como BAM, BONK ou KRACK.

Novamente, temos um som de um impacto do pé com algum outro elemento, como nos passos. Aqui, no entanto, a região de contato entre o pé e o outro objeto pode variar: o calcanhar, a ponta, a sola ou mesmo as costas do pé podem ser usadas para chutes. Da mesma maneira, enquanto nos passos o elemento de contato é sempre o chão, nos chutes pode haver impacto contra objetos de diversas consistências, incluindo o corpo humano. A reduplicação é possível, mas rara, consistindo em apenas uma repetição e representando chutes sucessivos.

Nesta amostra, não encontramos nenhuma correspondência, mesmo parcial, entre as formas em português e em alemão. No português, a distinção entre as onomatopéias para chutes e socos parece ser a escolha de vogais, utilizando para os últimos as vogais posteriores, aliadas às consoantes nasais, para dar a idéia de uma pancada surda, breve e interrompida subitamente. O alemão parece diferenciar mais os sons percebidos em chutes, utilizando maior diversidade de vogais. No entanto, também em alemão há um maior uso de nasais, "escurecendo" as vogais, assim como em português.

Interessante é a presença de africadas e onomatopéias com duas sílabas, o que nos faz pensar em um som composto - em mangás, os chutes são geralmente associados a lutas de artes marciais, nos quais freqüentemente há um grande deslocamento da perna até o ponto de impacto no oponente, seguindo depois para uma outra posição. Assim, podemos sugerir que as onomatopéias em alemão não se restringem ao momento do impacto, como parece ser o caso em português, mas sim apresentam um componente representando movimento, anterior ou posterior ao impacto em si (TSCHANK; BADONK; BADUSCH; ZADUSCH). Esta hipótese também necessitaria de maiores investigações. 


\section{c) Ruído ambiente: folhas ao vento}

\section{Alemão:}

RIESEL RIESEL / SCHRR / SCHRRSCH / SCHSCH

Português:

\section{FLOWN... / FSH FSH / FWAP... / VOUSH... / VUSH VUSH / VWOOOOOOSH / VWOSH... / WOOOOOSH / WOOOSH!}

Organizadas foneticamente:

Alemão: RIESEL (RIESEL) / SCHRR / SCHRRSCH / SCHSCH

Português: FLOWN / FSH FSH / FWAP / VOUSH / VUSH (VUSH) / VWOSH / WOSH

Temos aqui onomatopéias completamente diferentes daquelas empregadas para passos e chutes. O som a ser reproduzido é contínuo ou ao menos intermitente, causando a recorrência em ambas as línguas e sendo, em português, reforçado pelo uso da pontuação, especialmente das reticências. Pela primeira vez, encontram-se onomatopéias formadas apenas por consoantes (na quase totalidade das ocorrências em alemão e em apenas uma ocorrência em português). Novamente temos, em alemão, um exemplo de onomatopéia descritiva: RIESEL (RIESEL), derivada de rieseln (cair mansamente, murmurejar).

Nota-se a esmagadora presença de fricativas, tanto em posição inicial como final, o que é claramente motivado pelas características do som a ser reproduzido. As consoantes fricativas apresentam as mesmas características acústicas do ar em deslocamento, percebido através da sua fricção contra elementos do ambiente. Aqui temos um bom exemplo de como as histórias em quadrinhos levam à criação de novas onomatopéias. Não há, em alemão ou em português, uma onomatopéia consagrada para "folhas ao vento", assim como há, por exemplo, para um espirro (atchim! / hatschi.). Desse modo, é necessário ater-se às características do som a ser reproduzido e criar novas onomatopéias de acordo com as características de cada língua.

Com exceção da onomatopéia descritiva RIESEL em alemão, todas as ocorrências, em ambas as línguas, iniciam-se por fricativas. Contudo, as fricativas utilizadas em cada língua não são as mesmas ou são utilizadas diferentemente. Em português, temos fricativas lábio-dentais (F, V) em posição inicial e a sibilante $\mathrm{SH}$ em posição final (onde também há exemplos de nasal e 
plosiva), enquanto em alemão temos sempre a sibilante $\mathrm{SCH}$, tanto na posição inicial como na final. Não há nenhuma ocorrência comum a ambas as línguas, o que novamente mostra que as onomatopéias não são simples representações icônicas de um som "real", mas sim formas construídas a partir das características fonológicas e fonotáticas de cada língua, que visam a evocar no leitor uma experiência sonora associada a uma certa situação.

Com isto em vista, é interessante notar que, embora aqui se trate claramente de um "ruído", ou seja, um som completamente sem harmonia, as onomatopéias em português tendem a utilizar vogais e ditongos e a constituir sílabas, utilizando as reticências para indicar a intermitência do som, enquanto em alemão há a multiplicação das consoantes. As vogais presentes em português são a central baixa e as posteriores fechadas, sugerindo sons mais graves. Pode-se considerar também uma possível influência do inglês, devido ao uso de ditongos com a semivogal W (como em FLOWN, VWOSH), inexistente em português.

Pela primeira vez, há ocorrência de onomatopéias sem a presença de vogais, em ambas as línguas, com apenas um exemplo em português e a totalidade dos exemplos no alemão (excluindo-se a onomatopéia descritiva RIESEL). A ausência de vogais no alemão pode ser devida a uma maior tolerância silábica à combinação de várias consoantes, já que o alemão apresenta muito mais possibilidades de encontros consonantais do que o português, assim como sílabas que comportam muito mais consoantes (cf. CAMARGO 1972). De qualquer modo, as ocorrências alemãs são formadas apenas por líquidas, fones de alta sonoridade, que se aproximam às vogais no que se refere ao núcleo da sílaba (cf. KOHLER 1995: 73s. e 108s.). Algo similar acontece na única ocorrência sem vogais em português, formada por uma fricativa e uma líquida (FSH).

Em alemão, a onomatopéia descritiva RIESEL deriva de um verbo que não tem correspondência em português e que descreve um evento que seria normalmente associado a uma experiência visual: o verbo rieseln é utilizado para designar a queda suave de algo formado por pequenas partículas, como neve ou chuva fina. No entanto, a onomatopéia dele derivada é usada aqui para um evento sonoro, o vento nas folhas, causando um efeito bastante interessante: a informação semântica de "material particulado em movimento" aplica-se perfeitamente às folhas ao vento, evocando secundariamente o ruído causado por elas. Novamente, temos um bom exemplo de onomatopéia não-icônica, já que não tenta reproduzir o ruído específico das folhas, mas parte de um signo 
lingüístico já pertencente ao sistema do alemão. É também interessante que o verbo em alemão tenha sido formado provavelmente a partir de uma onomatopéia ótico-mimética, na acepção de Koller, o que ilustra a importância dos processos de formação de onomatopéias para o crescimento do léxico da língua (cf. LiMA 1999).

\section{Considerações finais}

Vimos aqui que as onomatopéias e interjeições, que recebem normalmente pouca atenção da gramática tradicional, apresentam-se como um campo fértil para estudos lingǘsticos quando examinadas em seu "habitat natural" das histórias em quadrinhos. A integração desses elementos na linguagem dos quadrinhos obriga ao seu uso constante e à criação de novas formas, especialmente quando da tradução de produtos importados.

Examinando uma pequena amostra de onomatopéias e interjeições em mangás japoneses traduzidos para o alemão e o português, pode-se constatar que há pouquíssimas formas comuns a ambas às línguas, o que reforça a tese de que as onomatopéias não são completamente icônicas, apesar de serem acusticamente motivadas, mas sim contêm um forte componente lingüístico, tendendo a seguir as características fonotáticas de cada língua. As diferentes formas encontradas para um mesmo evento sonoro demonstram que eles são percebidos de modo diverso por membros de diferentes comunidades lingüísticas. Isso mostra que o importante na criação de onomatopéias em histórias em quadrinhos não é a reprodução fiel e realista de um determinado som, mas sim, a criação de um signo gráfico-lingüístico que, aliado ao desenho, comunique a intenção do autor.

Embora tanto onomatopéias como interjeições sejam entendidas como a representação escrita de eventos sonoros, as interjeições que servem à expressão de estados de espírito apresentam um alto grau de inserção no léxico de cada língua, com pouca produção ad hoc. As interjeições são compostas basicamente de vogais, utilizando a recorrência e a pontuação para modular a intensidade e a duração do som, bem como para reproduzir a entoação.

As onomatopéias, por sua vez, servem à reprodução de eventos sonoros não produzidos por falantes, como ruídos e outros sons do ambiente, ou à representação de eventos não-sonoros através de onomatopéias visualmente motivadas. Dessa forma, nas histórias em quadrinhos atuais, as onomatopéias também podem servir como expressão de estados de espírito, ao dar uma 
expressão "sonora" ou "textual" a ações que, na realidade, não as têm. Exemplos disso são as onomatopéias usadas para o que podemos descrever como "cerrando os punhos", "olhar fulminante" e "estado de tensão" nos exemplos apresentados anteriormente e que mereceriam um estudo específico.

Apesar das diferentes formas em cada língua, nota-se, porém, que as características principais do som a ser reproduzido se mantêm e definem as linhas básicas para a formação das onomatopéias: se é um som breve ou longo, se é intermitente ou interrompido bruscamente, se é mais surdo ou mais agudo. Com base nessas características fundamentais, cada língua seleciona os fones que julga mais adequados para representá-los, sendo aqui onde as diferenças se revelam. Um bom exemplo disso são as onomatopéias utilizadas para o som do vento nas folhas, no qual a característica básica exige o uso de fricativas, mas para as quais o alemão dá prioridade às sibilantes, enquanto o português utiliza as lábio-dentais em posição inicial.

Há, portanto, dentro de cada língua, regularidades quanto aos fonemas usados e os "temas" ou "sons" que representam (tipo de fonema, duração, intermitência...). Tais regularidades levam à criação de um "vocabulário" específico e não mais apenas ad hoc, que é dominado pelo público leitor do mesmo modo que os demais elementos da linguagem dos quadrinhos, emprestando peso à tese de que "interjeições não são características de uma comunidade lingüística, mas sim de uma comunidade textual" (cf. TRABANT apud KOLLER 2003: 175).

Além das onomatopéias próprias de ou criadas por cada língua, nota-se ainda, como mencionado pelo Houaiss, a presença de onomatopéias e interjeições "importadas" ou "traduzidas" do inglês (como ARGH, GASP, OUCH, FLOWN, WOSH), as quais, porém, estão pouco representadas na amostra, o que indica que não se pode dizer que há "dominância" da língua inglesa nas onomatopéias e interjeições em histórias em quadrinhos alemãs e brasileiras.

Ainda em relação a empréstimos lingüísticos, outro fato interessante são as formas possivelmente emprestadas diretamente do japonês, como NYAHAHA, GYAH, WAH. Esses empréstimos parecem restringir-se às interjeições, o que, aliado à observação de maior número de formas comuns entre as duas línguas estudadas, pode apontar para o fato de que interjeições são, realmente, mais universais, talvez devido a vocalizações espontâneas associadas a reações comuns a todos os seres humanos. Nas onomatopéias, por outro lado, cada língua percebe o material sonoro de uma maneira particular, compondo 
onomatopéias ad hoc que depois podem passar a integrar o léxico da sua linguagem dos quadrinhos.

Dentro desta pequena amostra, nota-se uma maior variedade de formas para as interjeições em português, enquanto o alemão apresentou maior variedade de formas em onomatopéias. No entanto, dado o tamanho reduzido do corpus, podem-se apenas apontar tendências e levantar hipóteses, sem resultados conclusivos.

Em geral, pode-se afirmar que as interjeições, nas duas línguas, são constituídas em sua grande maioria de vogais, apresentando várias formas presentes comuns a ambas. No entanto, tais formas são sempre uma minoria no total de ocorrências. Na amostra, as vogais mais utilizadas foram A e $U$, seguindo-se as vogais O, I e ditongos (AI, AU, YA, UA, WA). A vogal E está muito pouco presente, comprovando a observação do Lexikon para o alemão (cf. HAVLIK 1981: 46). Há grande presença de aspiração final ou inicial em ambas as línguas, representada pela letra $\mathrm{H}$. A pontuação é elemento importante e muito utilizado, sendo mais freqüentes as reticências, o ponto de exclamação e o ponto de interrogação, nessa ordem.

Já nas onomatopéias analisadas, nota-se o predomínio de consoantes, com vogais atuando apenas como núcleo de sílaba ou estando totalmente ausentes. As formas comuns às duas línguas tornam-se mais raras ou mesmo inexistentes. Nas duas línguas, predominam sons plosivos e fricativos em posição inicial, comprovando novamente os resultados do Lexikon para o alemão (cf. HAVLIK 1981: 45s.). Embora haja padrões fonético-fonológicos básicos comuns em ambas as línguas, associados ao "tema" ao qual se referem, as onomatopéias da amostra diferem muito nas duas línguas, o que pode inclusive inviabilizar a compreensão por parte de um leitor estrangeiro que não as conheça. Isso mostra que é tão necessário traduzir ou adaptar as onomatopéias em histórias em quadrinhos quanto o texto em si, o que ressalta sua condição de signos lingüísticos, mesmo que diferenciados em relação aos demais elementos do léxico.

A presença de onomatopéias e interjeições no cotidiano já há muito extrapolou as histórias em quadrinhos. O Lexikon lembra que elas são encontradas em cartazes, em filmes, na propaganda e até mesmo em textos de instrução (cf. HAVLIK 1981: 13). A crescente integração entre a linguagem do texto falado e escrito e a linguagem da imagem na sociedade atual apresenta-se como um instigante novo campo. Cabe aos estudiosos da linguagem reconhecer essa evolução e lançarem-se à descoberta das novas possibilidades que ela 
apresenta.

\section{Referências bibliográficas}

BArbieri, D. Los Lenguajes del Cómic. Barcelona / Buenos Aires / México, Paidós 1998.

Bechara, E. Moderna Gramática Portuguesa. Rio, Lucerna 1999.

CÂmara JR. J. M. Dicionário de Lingüistica e Gramática. Petrópolis, Vozes 1977.

Camargo, S. As consoantes do português e do alemão. São Paulo, FFLCH/USP 1972 (tese de doutorado não publicada).

Houaiss - Dicionário Eletrônico da Lingua Portuguesa. Rio, Objetiva 2002 (CD-Rom).

Dubois, J. et. alii. Dicionário de Lingüística. São Paulo, Cultrix 1998.

DuDEN - Deutsches Universalwörterbuch. Mannheim, 2003 (CD-Rom).

DuDEN - Die Grammatik. Mannheim / Leipzig / Wien / Zürich, Dudenverlag 2005.

Eco, U. Apocalípticos e integrados. 6a . ed. São Paulo, Perspectiva 2004.

ENGEL, U. Deutsche Grammatik. Heidelberg, Groos 1988.

HAVLIK, E.J. Lexikon der Onomatopöien. Frankfurt a.M., Fricke 1981.

KoHLER, K. Einführung in die Phonetik des Deutschen. Berlin, Erich Schmidt 1995.

Koller, E. "Interjektionen, Deutsch - Portugiesisch". In: BLÜHDORN, H.; SCHMIDT-RADEFELD, J. (Ed.). Die kleinere Wortarten im Sprachvergleich Deutsch-Portugiesisch. (Rostocker Romanistische Arbeiten 7). Frankfurt a.M. Peter Lang 2003, 173-211.

KÜHN, P. "AHA! Pragmatik einer Interjektion". In: Deutsche Sprache 4, 289-297.

LEHMANN, K. Franæösische Werbung aus semiotischer und rhetorischer Sicht. Frankfurt a.M., Peter Lang 1998.

LIMA, C.D.M. Onomatopéias e palavras onomatopaicas, uma revisão no processo de formação de palavras. Uberlândia, UFBA-MG 1999 (dissertação de mestrado não publicada)

Watsuki, N. Rurouni Kenshin. Vol. 15. Tóquio, Shueisha 1997.

Watsuki, N. Samurai X. Vol. 29. Tradução de Luiz Octávio Massato 
Meireles, S. - Onomatopéias e interjeições em histórias em quadrinhos em língua alemã

Kobayashi. São Paulo, JBC s/d.

Watsuki, N. Kenshin. Vol. 15. Tradução de Christine Steinle. Berlin, Egmont 2002. 